\title{
Transforming into Practice a Concept: Accounting as an Instrument of Social Justice
}

\author{
Athar Murtuza \\ Seton Hall University, South Orange, NJ, USA \\ Email: athar.murtuza@shu.edu
}

How to cite this paper: Murtuza, A. (2019) Transforming into Practice a Concept: Accounting as an Instrument of Social Justice. Open Journal of Social Sciences, 7, 412-443.

https://doi.org/10.4236/jss.2019.78031

Received: July 30, 2019

Accepted: August 26, 2019

Published: August 29, 2019

Copyright $\odot 2019$ by author(s) and Scientific Research Publishing Inc. This work is licensed under the Creative Commons Attribution International License (CC BY 4.0).

http://creativecommons.org/licenses/by/4.0/

\begin{abstract}
This article is a follow-up to an earlier article (Henry, Murtuza, \& Weiss, 2015) [1] that discussed the potential of accounting to do much more than prepare financial statements for investment decisions. The three authors argued in the earlier paper that accounting besides producing financial statement can also be an instrument of social justice. This paper, written by one of the three authors shows how the conceptual potential of accounting to be an instrument of social justice can be transformed into accounting pedagogical practices. In other words, instead of being merely concerned with "counting," accounting can also be seen as being connected with accountability and the ability to account for and explain, the organizational reality. An introduction is provided in Section 1. In Section 2, this paper starts by recapitulating the earlier paper and then describing how this paper will build on the foundation the original paper provided. In Section 3, the use of literary works to help teach accounting and information engineering concept is illustrated. The last section provides suggestions to bring about an enrichment of the accounting and business curriculum. The last section is adaptation of a proposal the author wrote for his department. While one does not yet know how the proposal will be perceived by the department, the business school and the dean, it seems a worthy idea to make it a part of public domain so it could help others get started on their approaches to improving their teaching and the material they use.
\end{abstract}

\section{Keywords}

Accounting Education, Ethics, Accountability, Social Justice, Wallace Stevens, Anecdote of the Jar

\section{Overview}

In the "Original Paper" (Theresa, Murtuza, \& Weiss, 2015) the authors sug- 
gested the need for changes in the approach used to teach accounting. That paper argued that one should not limit the purpose of accounting to be the instrument for preparing or certifying corporate financial statements aimed at maximizing share-holders' wealth. The paper suggested that instead of merely reporting financial statements, accounting's roles ought to include providing stakeholders information that can also be used to hold organizations both public and private, accountable for how they used their resources and impact sustainability.

Continuing in the spirit of the previous paper, this paper also suggests that the business and the accounting educator redefine or at least encompass as a part of the discipline's function, the role to be a discourse of accountability. In doing so they well help it realize its potential role as an instrument of social justice.

To accomplish this change, each academic institution must critically examine its curricula to see that it includes topics and material that would inculcate and help induce students toward ethical and moral behavior. Such advocacy suggesting the business and accounting academics undertake the examination of the curriculum that is an onerous requirement on the academics and their institutions, but the seeming enormity can be mitigated by realizing that most institutions already do such examination in order to be accredited or continue to be so. The institutional introspection is the underlying rationale for the academic institutions seeking accreditations from appropriate bodies, such as the Association to Advance Collegiate Schools of Business International (AACSB). A periodic imperative for self-examination and introspection that is mandated by accreditation should also be used to bring about curricular changes that will address the need for the sense of societal justice being inculcated among the students. Accreditation should not simply be a seal of goodness, it could also promote institutions to be better, more accountable for how they deploy their resources and to improve the learning imparted to the students. This paper takes the view that institutional introspections colleges undergo should also help improve the infusion of not only technical skills such as the comprehension of the Generally Accepted Accounting Principles (GAAP) within the accounting curriculum but also help promote ethical and moral behavior. The self-study reports for the AACSB accreditation can follow the notion that it like "Procedures Documentation Ought to be Illuminative, Not Just Archival" (Murtuza, 1994) [2].

\section{Recapping the Original Paper}

Even though the phrase "discourse of accountability" was not specifically used in the Original Paper, but, the paper implicitly sought to make accounting be just that, specifically by using Moses Pava's suggestion as the framework to build on in the earlier paper. Pava (2010) [3] recommends for a change in the governing metaphor of accounting from "accounting as finance" to "accounting as ethics." Such a change in the perception of accounting would allow accountants to rise above their self-interest and promote the public interest rather than ignoring it 
out of a sense of loyalty to their clients. This paper adapts Pava's recommendation, which agrees with the notion that accountants should pay more attention to what Chief Justice Burger remarked on a case brought before the US Supreme Court: "this public watchdog function demands that the accountant maintain total independence from the client at all times and requires complete fidelity to the public trust (1984)" [4].

Seeing accounting as a discourse of accountability would help nudge the profession to see its role to not just archive but also illuminate the use of resources presented through the financial statements. The fidelity to the public trust should direct them to see financial statements are not just for the financial investments, but to also illuminate their potential for social justice. Accountants must see their role to help illuminate the organizational use of resource to outcomes that may not only satisfy shareholders but also contribute to the common good. Seeing accounting to be not just counting but the instrument of accountability can shift commerce to move from profit maximization to social justice. In fact accounting construed as a discourse of accountability can in fact perform both "sacramental" and "prophetic" roles. By insuring that the financial statements tell the truth, accountants are helping to make the accounting information akin to the sacramental, truthful. In seeing that the resources, economic, human, and social are not being misused or abused, the accountants can also be prophetical.

The Original Paper also suggested that imparting increased financial literacy to all should be a function of accounting and finance professoriate. Since it will make the public at large to then to more likely impact the politician and the regulatory bodies into being more willing to prevent predatory behavior on the part of business. Greater financial literacy will likely motivate public to better insure that the politicians are not slacking in their oversight function and giving in to corporate pressures at the expense of public at large. While discussing accounting failures and the global financial crisis, the paper suggested the compelling need for changes in the current accounting education pedagogy. The importance of promoting an accountable use of public and private resources should lead one to borrow from the European Reformation during which the laity was also educated and it did not rely on the clergy alone to understand the scriptures. In a similar mode the use of public and private resources should be looked over by financially literate public at large, in order to promote a more accountable and equitable governance and help prevent the accumulation of wealth in few hands as is under way around the world.

The original paper also noted that a greater amount of efforts and resources should be dedicated to infusing ethics and social responsibility in the curriculum. The number of educational institutions that have a course dealing with accounting ethics and professional code should expand. A professional body such as AICPA seeks to encourage this by having significant amount of material pertaining to its professional code. The amount of such material in the CPA exam is on par with topics such as cost and tax, but the number of colleges that have ac- 
counting ethics course does not compare well with those that have courses in tax and cost accounting. Adding such a course to the curriculum will be helpful, but on its own will not suffice to change the business education environment that elevates profit maximization above ethical and socially responsible business activities. The notes must be repeated to be impactful, just like the basic notes in great symphonies are repeated as suggested in the Original Paper. In the Original Paper a call was made for not entirely dividing faith-based injunctions from not only the ethics textbook as is the case with most of the texts available, but from business education in general. The paper cited views from Pope John Paul [5], Martha Nussbaum [6], Amartya Sen [7], and Sumantra Ghoshal [8] to support its argument. It also took note of how focus of accounting courses seems to over-indulge on the technical/book keeping aspects of accounting. They are devoted almost entirely on preparing financial statement and very little on impact accounting has behaviorally and on society at large. Rarely one sees a course devoted to accounting communication. They reduce accounting to mere counting and ignore concerns for accountability and to account for the organizational reality with which accounting must be concerned with.

The paper suggested a more robust us of literature and humanities to explain accounting and information engineering. This is what this paper will do next by illustrating how it can be done in an accounting course.

\section{Illustrating the Use of Literary Works as Part of Accounting Curriculum}

Trying to raise the students' awareness of the nature of the accounting information (epistemology!) as well as the process involved in the communication of information with the help of literary works and doing so within the confines of an accounting course is uncommon. As noted by Plump and Van Buskirk 2015 [9], "there is relatively little written on the use of poetry as a pedagogical device in the management classroom." This part of the paper seeks to show how poetry could be infused within an accounting curriculum.

Such a use of literary works in the context of accounting courses seemingly fits the various definitions of creativity quoted by J. Daniel Cougar (1995) [10]. Among the definitions quoted by Cougar is the one by J. S. Bruner that sees "effective surprise" to be the essence of a creative approach. John Ciardi sees creativity to be imaginatively recombining known elements into something new, while the French mathematician Poincare equated the creative process with a fruitful combination that reveals an unsuspected relationship between facts, long known but wrongly believed to antithetical to each other. In order to merit classification as creative, an activity must be new or unique and it must have utility and/or value according to Cougar (Cougar, 1995, p. 14).

Using Wallace Stevens' poem "Anecdote of The Jar" to improve students' understanding of the accounting's origin, nature, limits, and methods, the epistemology of the discipline, can be creatively beneficial. Despite being seemingly "off the wall," trying to bring literature within the accounting curriculum has 
utility and it can be done with relative ease, without forcing accounting educators and students to read through verbose volumes like those of Charles Dickens and Herman Melville. Indeed, accounting professional were advised by James G. March at their annual meeting in 1986 [11] about the benefits of breaking down the barriers that divide information sciences such as accounting from disciplines comprising the liberal studies. Such divides have impoverished the two cultures, the same way the two cultures of arts and sciences were in the British academia, according to C. P. Snow, after the Second World War.

March in his address noted that literary works and theories can help decision making by assisting the users of information interpret the information provided. The intended and actual users of accounting information, according to March, interpret reports they are provided by the accounting departments of their organization. Accordingly, he told his audience made up of accounting professors and professionals that the notion of treating an accounting report the way one does a poem is not "entirely ludicrous" even if it appears to be a "strange vision." In asking accountants to treat accounting information with its "language of numbers, ledgers, ratios" as poetry, March sought to extend their horizons and expand comprehension. Information for March meant something more than simply filling in "the unknowns on a decision tree." For information professionals, it is not "entirely unworthy vision to say their accounts and reports can be richer in meaning than they are aware of or intend, and that they can enrich our sense of purpose and enlarge our interpretations of our lives" (1986, p. 44).

March's argument follows from his perception that the contemporary view of information engineering draws upon decision theory and links information to choice. However, according to March, the study of organizational decision-making literature demonstrates that decision-making as presented by decision theory does not fully appreciate the ambiguities inherent in making choices. When one analyzes the disconnect between actual behavior of decision makers and the recommendation of decision theory, one learns that often behavior introduces "elements of good sense not routinely recognized" by the theory. For March, the information systems that are "closely articulated with choices in the way anticipated by the decision theory" are often "incomplete." The solution for such lack of completeness, according to March, rests in blending the theories of choice in decision theory with the traditions of history, culture, and literature (pp. 31-32). The engineering of information would gain from such a synthesis.

March was seeking to show that choices available to decision makers are not as clear-cut as decision theory would make them out to be. This is often not brought out in the texts used in Business curriculum. Clearly students can be reminded that there exists a significant semblance between the organizational managers and the Danish prince of indecision. But Shakespeare's Hamlet would not have been all that better off by applying the decision tree technique to the question of "to be or not to be."Since the address given by March to AAA's annual meeting, it is becomingly increasingly familiar to come across research that uses the tools and ideas borrowed from literature and literary theory to study 
accounting. Interdisciplinary Perspectives on Accounting Conferences held in United Kingdom and its American counterpart, Critical Perspectives on Accounting Conferences routinely include papers in their program that study accounting using literary concepts and works. Accounting Journals such as Critical Perspectives on Accounting, Accounting, Auditing and Accountability Journal, and Accounting Organization and Society have published papers that also do so. A brief sampling of works that cross disciplinary divides is reflected in works by Heath (1987) [11], Thornton (1988) [12], Arrington and Francis (1989) [13], Moore (1992) [14], Cooper and Puxty (1994) [15], Walters-York (1996) [16] and Baker and Macintosh (1997).

On the other hand, a quick survey through accounting textbooks used for managerial and financial accounting show no citation to research that uses literary theory to study accounting. The references cited by widely known texts, such as Garrison's managerial accounting and Kieso's financial accounting, do not cite works similar to those by March, or those cited in the previous paragraph. Even the texts used for teaching accounting information systems courses downplay the human factors involved in communication.

Given such an absence of interdisciplinary approach in accounting texts, the value of using Wallace Stevens' "Anecdote of the Jar" in an accounting course becomes a potential useful tool for enriching students' comprehension about the nature of accounting. The Stevens' poem is not a lengthy work, it is not as verbose as $19^{\text {th }}$ century novel, and it can easily be fitted in the confines of the accounting courses. This is the reason to help bring to an accounting course what March encouraged, namely the use of literature and literary theory to better understand the nature of information. As noted earlier, even though a good amount of interdisciplinary research is available, it has not be brought down to classrooms judging from the dearth of cases or articles that show how literature could be incorporated in the teaching of accounting. Our concern in this section of the paper will be to show how Stevens' poem could be of use in making students see the divide between poetry and accounting is bridgeable-the two disciplines can enrich each other. As a caveat to the readers, this illustration does not suggest doing away with the traditional approaches to teaching accounting all together, instead it is only to induce teachers of accounting into using supplemental resources that will enhance their students' take-away from their accounting courses. The poem's notoriety can deduced from the 223,000 results brought up by the Google search engine in response to the question: "what does the jar represent in anecdote of the jar." The poem is widely available on the internet, including the following link: https://poets.org/poem/anecdote-jar:

I placed a jar in Tennessee,

And round it was, upon a hill.

It made the slovenly wilderness

Surround that hill.

The wilderness rose up to it, 
And sprawled around, no longer wild.

The jar was round upon the ground

And tall and of a port in air.

It took dominion everywhere.

The jar was gray and bare.

It did not give of bird or bush,

Like nothing else in Tennessee.

A poem made up of 75 words that include the title, describes the process that leads to placing the jar on top of a hill and its impact on the surrounding environment. It can be used to signify myriad of possibilities, among them Stevens' perception of the human cognitive process. In this paper the jar, a humanly constructed object is taken to represent the GAAP; and being placed on top of an uncharted hill is akin to drafting the accounting standards. Some orthodox literature folks may be disconcerted by the comparison, but the poem will survive such an use of it. As may be seen, it starts by describing a very human action, the placing of a jar upon a hill in Tennessee. The act by the persona: "made the slovenly wilderness/Surround that hill./The wilderness rose up to it,/And sprawled around, no longer wild." The human artifact, "gray and bare," was "like nothing else in Tennessee," and "it did not give of bird or bush." Still it was "tall and of a port in air," and more importantly, "took dominion everywhere." It must be realized that the jar had dominion only in that particular place. Outside that "wilderness" it loses its focusing capacity, just as without the jar, the "wilderness" becomes uncharted, no is longer colonized.

By juxtaposing the jar with an alien environment, the poem makes it the focus of what is an uncharted wilderness, according to the poem. Once it is introduced into the landscape, the landscape is no longer wild; the jar has taken dominion-like the Europeans took dominion and established colonies. The process described in the poem is not unlike what a hiker is likely to do if he finds himself in an uncharted and "slovenly wilderness." He is likely to find himself a landmark and then use it to chart his hike. In the same way, a surveyor has to fix his bearings before he starts on his survey. One could also compare the act in the poem to what in the discipline of rhetoric was once called nominatio, it refers to "the naming and listing of things ... the most basic act of consciousness in the world: the process by which man articulates the world to make it signify, and hence renders it inhabitable" (Kernan, p. 207) [17].

In addition to the representing the human cognitive process, the poem can also be used in an accounting course to show the similarities between the Generally Accepted Accounting Principles and the impact the Jar has on the environment in which it got put, placed. While using the poem in my accounting courses, I start with sharing with students the following outline:

- The jar in the poem has been made by a human being, a person;

- After being placed atop a hill; the jar becomes the focus of its surroundings and asserts dominion over the wilderness. 
- As a result, its surroundings are no longer wild. The wilderness can now be charted, mapped, measured, and described!

- One could say it has been Colonized! The way Europeans colonized their colonies around the world with only loot on their mind.

- With the help of a human artifact, the product of imagination and cognition, what was wild and uncharted now makes sense!

- One can then suggest that accounting is to an organization what the jar is to the wilderness in the poem. It is in effect holding not only a mirror to reflect the organizational reality, it is also illuminating it.

- Accounting is not just about COUNTING! It also means: to Chart, to Map, to Survey to Explain, to Describe and to Account for the organizational identity and to measure its performance.

- Making sense of an organization's nature, goals, and objectives is thus facilitated by the accounting information. The question remains how well does it accomplishes it. Is the representation of economic reality by accounting dollars free of ambiguity?

- The Jar is neither bird nor bush, hence how should it impact that which existed before the dominion was imposed.

o As a resource to use and exploit by virtue of having taken dominion.

o As a sustainable environment where the jar coexists with birds and bushes.

- What approach the Generally Accepted Accounting Principles ought to take in impacting the organizational attitudes towards the world which they inhabit and presume to represent.

In addition to help students see the comparison between the GAAP and the Jar in the poem, I have tried to pass on to students some additional material-the number of students who find the notion of a poem in an accounting course bewildering is significant. Such an orientation involves telling them that the function of accounting is presumed to be keeping track of an entity's activities and to evaluate its performance. It does so in monetary terms. Using dollars and cents, accounting is "holding a mirror up to nature," to use a phrase from Shakespeare. It can allow users by its reports to reflect upon the entity. To assist the accountants perform their reporting tasks, the profession has developed the generally accepted accounting principles. These principles and what the accountants seek to do with their help are means to do the very same function performed in the poem, nominatio-describing and naming the surrounding reality. The accounting principles as well as the accounting reports generated are very much like the Stevens' jar in the wilderness. They allow the users of those reports to chart their way and to measure a firm's performance. The contents of the financial and accounting reports, one must remember, are merely representations. They are not the entity itself yet they represent the organizational reality for many people, including investors who use them to put and call in the terminology associated with stock options. We are remiss in our perceptions of what accounting seeks to do, if we fail to see the accounting statements as other than a humanly constructed object, that is more ambiguous than crystal clear in what it 
represents, as many of socially constructed artefacts often tend to be.

To help students further in making the connection between the GAAP's and the Jar in the poem, I would recommend using words of Karen Pincus [18]: “at first glance, the financial statements appear very exact. After all, they focus on numbers - and figures, as Justice Louis Brandies once said, are a 'language implying certitude.' But, for the most part, the numbers in the financial statements aren't really to-the-penny-exact values. The numbers that appear in the financial statements are the product of a long series of financial accounting judgements" (Pincus, 1997, p. 1-3-67). The advice given by March to an accounting audience and cited earlier can also be useful here. Yet another advice would be that given by Richard Boland [19], who wants greater attention paid to human factors. His exhortation to be wary of scientism is grounded in his belief that "the logic of an organization is a lived logic. The contradictions of an organization are lived contradictions. Any fantasies that divert an accountant from a search for the lived experience of organizational members must be rejected" (p. 64). For Boland, there exist five fantasies that are promoted by scientism, which ought to be rejected by those preparing information. For Boland, these fantasies mistakenly suggest:

- Information is structured data

- An organization is information

- Information is power

- Information is intelligence

- Information is perfectible

Even though these fantasies flatter the accountant's role in the organization and self-image, they are "erroneous" according to Boland, and must be rejected. They also "lead to organizations that are monotonous, unchallenging, white-collar sweat shops." In addition, Boland argues that these fantasies fail to "respect the dignity of the individual worker" and "they deny the fundamental importance of interpersonal dialogue and the search for meaning through language for a human community" (p. 63). Even if one has some qualms about fully accepting Boland's views on the shortcomings of the empirical models of decision theory, still one must acknowledge the important relationship existing between information and its communication within an organizational context as well as between potential investors and their interpretation of financial reports. There is more than numerical significance to accounting information. Human factors and socio-political concerns are as important as the purely economic ones, and they do impact the development, communication, and reception of accounting information as well as the decisions that are made with its help.

The numbers such as earnings per share are often given the status of dogma, but investors ought to know what is involved in the calculation of numbers such as EPS. This knowledge could save them from wrong investments. The knowledge of the nature of net income in the case of labor unions can lead to better informed wage negotiations between the unions and management. Because net income is positive does not mean the entity is viable. All through the sixties the 
American steel producers were showing positive returns, even as they were sliding into outdated production modes because of antiquated physical plants. But this slide into obsolescence was not apparent to those who thought net income was reality itself. Accounting reports are no more than socially constructed artefacts, that can help us perceive an entity's performance. They are like Stevens' jar in the wilderness in that they allow us to chart the fiscal environment of the entity, but we must remember that they do so only tentatively. They could only be fully understood by users who keep in mind their nature and try to analyze them within their context.

Before moving to the next section of the paper, it is worth mentioning the use of a poem to explain GAAPs is in effect using literature as a surrogate for experiential learning. Literature and media helps readers and viewers experience life vicariously and as such it can help human being empathize and learn in much the same way experience can. Experiential learning seeks to impart knowledge by getting the student involved hands-on in the subject matter. The students find it far easier to remember an experience than a lecture. Games, business simulations, behavioral exercises in the classroom, and even case studies seek to bridge the gap between abstract lectures and experiential learning. Literary works can be a very valuable resource that those involved with teaching in business colleges have not well utilized. By using it more can help bridge the gaps between theory of business pedagogy and the experience of human behavior, what are akin to isolated silos. Literature for thousands of years has dramatized human behavior. The power literary works possess can be attributed to their ability to evoke empathy in their readers. While reading a novel, reciting a poem or watching a play, readers and audiences are able to experience vicariously the action being evoked. To paraphrase Shakespeare, literature may be seen as a mirror up to nature, human nature, that is. The power of literary works to evoke empathy and allow readers to vicariously experience what the literary work is evoking can be used by teachers of behavior in classrooms. Indeed, the literary works can serve as sources for vicariously experiencing life and through it behavior. In other words, one ought to be able to use literature as a surrogate for vicarious experiential learning.

Literary works can only be a supplementary resource in accounting courses. Texts that directly address the GAAP's will continue to occupy the center stage in the accounting curriculums in the United States as well as rest of the world. Still, one can see that literary works have the potential to provide accounting teachers with "interesting if not exciting" means to give their students a different perception of the issues involved in the communication of accounting information as well as understanding its organizational contexts. As we become ever more involved with knowledge management, it is imperative to learn that information, the life blood of knowledge, is much more than mere numbers, or for that matter electronic bits and bytes. Literature, it seems is not perceived as all that useful by many of the accounting professors, even more so by their students, however it need not be the case, this paper argues. One hopes that literary works 
can at least fill the gaps left when GAAP's are taught in accounting courses. The relationship between liberal arts and business curriculum need not be as that described by C. P Snow in his book about the divisions between the two cultures of arts and science that prevailed in the British universities some 60 years ago [20].

\section{Ideas That Can Help Infuse Social Justice in Business \& Accounting Curriculum}

As mentioned in the abstract, this section of the paper is actually a set of ideas contained in a proposal to my fellow members of the accounting department and the dean of the business school. Given that proposal such as those mentioned here invariably involve allocation of resources, carried out by processes that are highly political, outliers tend to lose out. No matter how I am trying to insure that these proposals are virtually cost free, one cannot forget that the resource allocation is not that different than the so-called third rail. I do not hold my breath about the likelihood of these proposed concepts turning into practice, still feel that there is no harm in making them accessible to a domain where it could be looked at by others. One must try to see the efforts expended are not a case of total loss, sunk costs. To hoard wealth, according to Islamic traditions and scripture is not favored by the Ultimate Provider of wealth and blessings.

In making my proposal part of a sequel to an earlier paper, it can be seen as brainstorming to help improve accounting \& business curriculum so that it is mission-related, accreditation facilitating, and most important, budget neutral-it will utilize the existing resources. The plan, or the "brainstorm" is named TRIPLE PLAY for its three parts, aims to:

- Make the drafting of the departmental/School strategic plan for AACSB self-study easier;

- Moderate the demands placed on business and accounting courses to squeeze more soft-skills related content;

- Improve the quality of education the school provides its students and make it more in keeping with the mission of the university.

The plan consists of three parts:

- Developing an on-line, multi-media course (using mostly, but not exclusively, movies, BBC and PBS documentaries, and NPR podcasts), to serve as an overture for the business curriculum ... It could perhaps be seen as an extended orientation to familiarize students with global business and what a business career would entail.

- Fleshing out the competences so they help promote learning and play a more optimal role in the learning process in place.

- Proposing new courses (the item which is most related to my interests) many of them have been gestating for some time, have been in progress, and one of them is offered seven times before it got sent to the comatose-nirvana. These courses will either be summer courses or perhaps independent studies so they do not interfere with my regular teaching load. 


\subsection{An Overture for the Business Curriculum}

- It will be developed as an Asynchronous On-Line Course.

- The course/extended on-line orientation is meant to make students have knowledge about the concepts and practices that undergird the business curriculum.

- I see it as an extended orientation, asynchronous on-line, for incoming and continuing students, which eventually could be taken by all entering business majors. In preparing its syllabus and teaching resources, it will rely on the six steps described in Bloom's Taxonomy of Educational Objectives for Knowledge-Based Goals: Knowledge, Comprehension, Application, Analysis, Synthesis, and Evaluation.

- In addition to making would be business majors better anticipate the content of the business curriculum, the proposed on-line course could also double as the business school's variation of a "business boot camp" for non-business students. There is one "boot camp" provided by the College of Arts and Sciences that runs for a week after the spring semester, but it serves a very small number of students. This proposed course would make for a broader access, allowing more students to take it during the academic year as a regular course, as an elective to explore business ethos.

- It could easily be offered as an "independent study" to keep it from conflicting my normal teaching load, which I assume is six or more sections of managerial accounting for the academic year. Some help from a graduate assistant will be helpful in implementing the logistics of teaching the course as would help from the folks that work with Instructional Technology on campus.

- It would be best taken by students as they start their studies, but it is likely not to lose its usefulness if taken later.

- As its initial offering, the Overture could center on the garment industry and its global context. To help underscore the importance of listening, the Overture, for its prologue will be using audio resource, NPR's special series called Planet Money's T-Shirt Project. The radio program PLANET MONEY followed the making of a simple cotton $t$-shirt through the global economy, the students taking the course will latch on for a ride to be introduced to the nature of Global Business.

(https://www.npr.org/series/248799434/planet-moneys-t-shirt-project)

- The course will use for its epilogue an analysis of the infamous Triangle Shirtwaist Factory Fire and its aftermath.

- The body of the course will rely on a "proper" text, suitable for a college level course.

- The course fleshed up by movies and documentaries, will not ignore readings and communication skills of the students taking-they will be asked to keep a journal to discuss their response to the course content and periodically make video presentation to document their "journey" aimed at discovering the global business world. 
- To help meet a part of their assigned readings, students will be required to subscribe to magazine such as The Economist or Bloomberg's Business Week. The material from the current issues and the magazine's archives will be part of the assigned readings. The readings will be assessed through online tests.

- This course will rely on teaching resources that focus on the mechanics of business functions as well as on critical thinking \& professional judgment, writing skills, presentation skills, ethical and legal decision-making, social responsibility, and individual accountability.

- By using movies and documentary as a teaching resource, the course will underscore that communication as broadly defined to include listening, watching, and making sense and is not confined to a classroom with an instructor serving as a sage on the podium.

- The instructor's role will be to combine being a sage and a tour guide. But in addition, the course will follow the footsteps of such as Dante, who learned from Virgil, Arjuna who learned from Krishna, and what Iqbal learned from Rumi. It is about becoming a better person and not limited to skills a business person must have. The focus of the course is not only on the skills taught by business disciplines but also on how the subject matter impacts the individual student taking the course. Since it is an on-line course, the center stage will be on "Personal Accountability." Concerns like "civic engagement," reflexivity, and a variation of Ignatian spirituality will be emphasized.

- As an online course, assignments would be structured to emphasize "personal accountability" on the part of students. They would need to engage with the material in a timely manner, before they move to the next assignment.

\subsection{Fleshing out the Competencies}

Before discussing how the Stillman competencies could be used in a more optimum manner, it is best to describe what they are. In the following section, paper describes them using the material available on the web.

\subsection{The Competencies}

As described in the catalog and the web, the Stillman Competencies are as follows:

(https://www13.shu.edu/academics/business/assessment-competencies.cfm)

- Critical Thinking: This competency refers to the ability to identify relevant issues or variables, analyze their interrelationships, and conceptualize solutions for specific problems. Inherent to this competency are proficient thinking in abstract terms, being able to see the "big picture", and understanding how the various parts of an organization or an idea fit and function together.

- Communication: This competency refers to the ability to communicate effectively, in writing and orally, with people of diverse business and professional backgrounds, both within and outside the organization. 
- Ethics and Social Responsibility: This competency refers to the ability to recognize and understand the accepted principles of right and wrong governing the conduct of business people and the ability to recognize and consider the social consequences of economic actions when making business decisions, given a presumption in favor of decisions that have good economic and social consequences.

- Teamwork: This competency refers to the ability to work with others as part of a team. The focus here is on developing an understanding of the principles of teamwork: working toward a common goal, sharing leadership responsibilities and authority, sharing power, sharing information to utilize resources fully, loyalty and collegiality, and building and maintaining personal and professional relationships.

- Technology: This competency refers to expertise in utilizing technology to improve productivity. The focus is to develop both computer literacy (that is, how to use computers) and information literacy. Specifically, knowing how to find and gather relevant data from various sources, organize, summarize and analyze them, and create meaningful and effective information for making business decisions.

- Change Management: This competency refers to the ability to respond to, and/or initiate change. The management of change competency is focused on the students' skills in four areas: managing change within oneself $\mathrm{B}$ as one matures and grows, managing change within organizations, understanding and responding to the dynamic domestic and global business environment, and solving creatively business problems generated by a changing environment.

The core curriculum for undergraduate students in the Stillman School of Business is assigned the primary responsibility for the development of the students' professional competencies in six areas described above The faculty develop students' skills in these competencies primarily in the core courses of the undergraduate curriculum. The assessment process ensures that students' competencies in the six areas are, in fact, developed in the course of their undergraduate studies. The core curriculum of Business school comprises:

Accounting (6 credits); Economics (9 credits); Management ( 6 credits); Marketing ( 3 credits); Finance ( 3 credits); Quantitative Analysis ( 6 credits);

Law (3 credits); Management Information Systems (3 credits); Integrative Courses (6 credits).

All business students must participate in the assessment process in order to graduate. The assessment process is a key component of the students' undergraduate education. It enables our faculty to monitor the quality of our undergraduate program and continuously improve and update our curriculum. It consists of the sophomore and senior assessment panels component where students analyze a current business situation and are evaluated by outside business practitioners. This part of the assessment model enables students to gain confidence 
and better understand the scope of the real business world. Additional detail about the competencies and the assessment process are described below.

The objectives of the undergraduate assessment are:

1) To ensure that students are developing their mastery of the five competencies as well as their skills in the functional disciplines of business, and

2) To improve the core curriculum continuously on the basis of feedback from the assessment process.

The assessment process consists of four phases.

1) Pre-Assessment.

2) Sophomore Assessment Panels.

3) Senior Assessment Panels.

4) The Final Assessment.

As a requirement for graduation, students participate in the pre-assessment and the final assessment, and also in one of the two assessment panels. The phases of the assessment are described below and are followed by Guidelines for Integrity and Professionalism at Assessment.

1) Pre-Assessment

All incoming freshmen students complete a vocabulary test where they are required to define key terms in four of the five competencies: change management, communications, teamwork, and technology. The key vocabulary terms were selected from the textbooks used in our undergraduate core courses. In addition, students take English and Math skills tests. These tests are administered during Freshmen Orientation.

2) Sophomore Assessment Panels

Each academic year, approximately half of the sophomore class of business students are randomly selected to participate in the assessment panels. We notify the students who were selected in October. In November, they receive official notices of the specific dates and times of their panels. Generally, the Sophomore Assessment Panels take place in February of the following calendar year. The students selected MUST participate in the assessment panels. Their participation is MANDATORY, not optional, and is also a requirement for graduation.

Approximately two months before the panels, students receive the names and e-mail addresses of fellow students who were assigned to be their team members on the panel (each team will consist of 4 to 6 students). Students also receive the materials for the assessment session, including the case(s) that the teams will be required to present, case questions, and individual exercises. On assessment day, each team presents answers to the case questions before several business practitioners who evaluate its work. During the presentations, students are required to use technology to enhance the delivery of the material presented.

In addition to the team presentations, each student completes two individual assignments. One assignment requires the student to write a short essay and the other assignment requires the student to demonstrate proficiency in a selected business skill via the utilization of technology. Students also prepare a self-evaluation of their individual performances in the teams and evaluate the 
contributions of fellow team members. The assessment panels last approximately two and a half hours. About six weeks later, students receive feedback about their performances.

3) Senior Assessment Panels

Each year, all Stillman school Seniors who did not participate in the Sophomore Assessment Panels are required to participate in the Senior Assessment Panels. Like in the Sophomore Assessment Panels, these panels include both teamwork and individual assignments. The logistics and plan used for the Senior Assessment are similar to those of the Sophomore Assessment Panels described above.

4) The Final Assessment

5) This phase consists of the students' work in two capstone courses-Business Policy and the Global Business Colloquium - where, among other tests, students retake the competency vocabulary test and resubmit writing samples.

6) Guidelines for Integrity and Professionalism at Assessment.

The assessment process is a key component of out the undergraduate program at the Stillman School. We expect our students to excel in both the team and individual components of the assessment process and to follow the guidelines below:

- Work hard to contribute to the work of their teams and master the teamwork competency.

- Recognize and fulfill their obligations and assigned roles within their teams.

- On assessment day, put forth clear presentations using concepts learned in class.

- When making their presentations before business professionals, students must dress, communicate and conduct themselves professionally and in a business-like manner.

- Observe the highest standards of integrity and honesty in both their teamwork and individual work. That is, not share the teams work with students outside the team, work individually with no outside assistance when required, and list clearly and accurately the references for any material used.

In the rest this section, the paper suggest how make more optimum use of them. Not many universities have similar resource available to them. Hence they are worth greater use of them to help insure the education is not limited to the classroom lecture.

\subsection{How to Make Optimum Use of the Competencies}

This proposal suggests that the Stillman competencies be treated in a manner analogous to so-called "soft skills." The competencies should become much more than a tool for assessment, even though they do a very good job of assessments, doing it superbly. The competencies will back up the acquisition of softer skills, something one should not delegate entirely to other units of the university or even the business core. They can link the Overture, proposed as a part of this proposal and the Business core courses by sharing the development of students' 
"soft-skills". Thus they will relieve the pressure on the core courses to develop soft skills as well as the technical skills. We could and should flesh up the Stillman competences since more rigor never hurts the quality of education we seek to impart.

We have the technology already available and there is an abundance of resources on web that are also freely accessible. In strengthening the demands for greater involvement by students in their own learning, which is what this part of proposal seeks to do, one can use the existing resources, such as Blackboard and Microsoft Teams. Doing so can make avaluable addition to help promote and extend students' learning beyond the classroom enclosures. There is nothing better than the competencies to make our students realize that acquisition of skills, knowledge, and wisdom goes on even they are not gathered within the enclosures of the classroom, or memorizing a practice test for the impending exam the next day.

The competencies are already doing a good job as an assessment of learning; but we could also use them to develop students' learning to extend beyond the four walls of a classroom. I believe these Stillman competencies, in addition to providing assessment of learning, can also be leveraged relatively easily to enhance learning beyond the enclosures (time of the day, room, desk, and the imperative to focus on what the instructor is presenting) of the physical classroom. The fleshing out of competencies can help change the students' mind set about what and how the acquisition of learning, indeed the capacity for discerned judgements no less, involves. They can become the tool to promote and to assess Personal Accountability and related skills such as time management.

In order to expand the role expected of the competencies, we should start by building upon the definition of competencies provided currently, and quoted earlier. While those definitions are precise and for the most part functional, they can be improved upon: competency in communication is said to be "the ability to communicate effectively, in writing and orally, with people of diverse business and professional backgrounds, both within and outside the organization." What is missing is the ability to listen or the use of visual communications. It would also be an improvement if the definition was to mention the inter-relation between communication, information and human behavior. These improvements/enhancement can be easier to accomplish if done asynchronously on-line. Since in core courses instructors are under pressure to teach the subject matter so that the behavioral aspects of information engineering get little or no attention in accounting courses and if they do, it is only a token gesture.

Upon declaring the intent to major in business, students should be asked to start working on their competencies by looking at the material provided on the web or Blackboard pertaining to the competencies. They should be provided more than a mere paragraph about each of the five competencies. The material to enlarge the concepts the competency represent is easily available on the Web and by getting students' aware of it earlier will also improve how students use those competencies in their courses. Doing this will be improving the process 
being currently used, under which: "Each business core class is responsible for developing one or more of the competencies. Classroom experiences and assignments develop these skills which are later assessed."

This is where more can be done. The core courses have enough on their plate to cover. The amount of material pertaining to comptencies that can be infused in the core courses is bound to take second place to the primary intent of the core courses, which is to teach the subject matter. The core courses can and should be assisted in carrying out their assignment.

\subsection{Illustrating the Under-Optimal Use of the Competencies}

An important part of learning is to get the students engaged. We should be telling students that they are also responsible for developing these competencies. The core courses alone cannot help students develop them and such a development of competencies is an on-going process-not a stone to step over, but a cumulative process where stones turn into stepping stones, a ladder. That is the heart of the learning process and by impressing it upon students will also help develop personal accountability.

Using how managerial accounting, deals with its assigned competencies, one can illustrate the process currently used. Let me use how they are woven within the syllabus of the core course in Managerial Accounting to illustrate my point, that we can make more optimal use of the competencies.

The course syllabus reads: "This course will help students develop and/or enhance the following competencies." The syllabus goes to describe the three competencies:

- “Critical Thinking. Problem assignments and examinations will require that students use critical thinking skills to apply accounting concepts and principles to various situations consistent with a global business environment.

- Communications: Upon completing this class, students will be expected to communicate in terms of accounting consistent with the requirements our society demands within the business world. Specifically, the class project requires students to communicate in writing using accounting terminology in a formal report. The project also requires each student to give a formal oral presentation to the class.

- Technology: Students will be required to use Microsoft Excel to develop a spreadsheet that calculates financial ratios for their project company. In addition, students make an in-class PowerPoint Presentation."

Of the three description, the shortest one, Technology is the most precise and tangible. It is referring to the familiarity with Excel and PowerPoint, popular softwares used for spreadsheet and presentation. The students can comprehend what is the task being mentioned, albeit with some help. The project assigned to fulfill the task of inculcating technology takes the form of a project involved with using software to calculate and develop a cost function is worthwhile, one can do more to let students know how technology is impacting how accounting is practiced. 
To meet the requirement of communication competency, the students are asked to discuss a case and present to their class using power points. The presentations are done instead of taking the final exam on the assigned day. Since the courses has a combined final for all of its sections which could range from four to nine each semester. I have allowed students to videotape their presentation and to self-critique it, instead of a live presentation. Watching themselves give the taped presentation is a useful way to let them observe how they come across. It is valuable enough to replace a live presentation during the finals' week when there are enough stresses to deal with.

Both the live presentation or a taped one are good practice for getting students accustomed to speaking to a group. But that is only one facet of communication. To the given definition of communication competency, one should add listening and comprehension as well, since they impact effective communication. I would like to also add the impact communication of accounting reports can have on individuals preparing them, the organization for which they work, and on the community, national economy, and the environment.

The most ambiguous of the three definition is the description of critical thinking, since it never explains what is critical thinking. By putting it alongside the definition from Wikipedia, can illustrates what the syllabus' definition is lacking:

Critical thinking is the analysis of facts to form a judgment: The subject is complex, and several different definitions exist, which generally include the rational, skeptical, unbiased analysis, or evaluation of factual evidence. Critical thinking is self-directed, self-disciplined, self-monitored, and self-corrective thinking. It presupposes assent to rigorous standards of excellence and mindful command of their use. It entails effective communication and problem-solving abilities as well as a commitment to overcome native egocentrism and sociocentrism.

(https://en.wikipedia.org/wiki/Critical thinking)

I confess while teaching the course, six sections of it during an academic year, I have not devoted a material amount of time to explain critical thinking or how it is developed in the managerial accounting courses. I hope to do so in the future at least in my sections. This will be made easier if critical thinking is more robustly explained and illustrated as well as introduced to the students as they enter the business school. Doing so will reinforce its importance for them and get them to anticipate their role in becoming more competent critical thinkers.

\subsection{How to Embellish the Competencies}

What I am suggesting is that the current sophomore and senior assessment, demanded of business undergraduates be supplemented by on-line testing of their familiarity with each one of the competencies. They should know what those competences are and by having them "study" with the help of resources made available to them, they are likely to become more adept in those skills. Those 
who know what those competencies represent will be better able to attain the goals associated with the competencies. Having the material on-line should allow us to assess the students' takeaway. Information technology is well suited to do so. It can track the time students devote to their competencies and one can administer on line assessment to measure the takeaway on the part of students. Such an addition to the current assessment process will motivate students to be engaged with the material. Some suggestions to engage students follow.

- As a part of the assessment of communication competency, they should be taking an on-line test of reading comprehension, grammar, punctuation, and syntax. Such on-line tests are easily developed.

- Knowing that reading comprehension, grammar, punctuation, and syntax is part of the assessment process, is likely to upgrade the attention students pay to written communication and reading comprehension in their courses.

- Right now most of our students will have a stressful time explaining what terms such as "change-management" should communicate and represents. Creating an on-line space, where to browse about life's constantly changing nature is for the good. A resource that comes to mind is the BBC series exploring the history of the world from two million years ago to the present through 100 objects

(http://www.bbc.co.uk/ahistoryoftheworld/about/british-museum-objects/) in the British Museum. It is freely available and can make student experience CHANGE. One need not have them read up on all the 100 objects, but certainly those pertaining to global trade would be an useful experience, One of the object discussed in the series is the credit card, knowledge about its development will help the students have an historical perspective which gives depth to what change is and how human beings seek to manage it.

- As part of the embellishment of business students' awareness of Ethics and Social Responsibility material should be available to them on-line. Such would be some material from the Catholic Social teaching and other faith traditions. Such material should include the following:

o A Link to the Vatican document: Vocation of the Business Leaders. The University of St. Thomas has prepared a number of power-point presentation that are available and would help students make more sense of the document. One could prepare objective questions dealing with the document, administered on-line to assess what students are taking away from their readings.

- Another document would be the APOSTOLIC EXHORTATION, EVANGELII GAUDIUM OF THE HOLY FATHER FRANCIS.

- Pope Francis' Laudato Si ("Praised Be"), an encyclical on climate and justice to "enter into dialogue with all people about our common home."

o There are resources available on the web developed through the efforts of other Catholic institutions of higher education that will facilitate the ability of students to apply such content to their educational and personal development.

- Teamwork must not be limited to working on a group project in an academic 
course. There is much more to it, in fact the relatively new phenomena of crowd sourcing is really an extension of teamwork as broadly understood. So are the concepts of decentralization and responsibility accounting, they are connected to the notion of organization as a team. Much more is accomplished through team efforts and students will be better if they know more about what it involves.

- One could build up the understanding of Teamwork by injecting the concept of Solidarity and Subsidiarity to its broader meaning. Infusing the discussion of what Catholic Social teaching say about Solidarity and Subsidiarity would make concept of Teamwork richer and make the school more in compliance with its mission.

o Solidarity from the perspective of the Catholic Social Teaching is well discussed at

http://www.catholicsocialteaching.org.uk/themes/solidarity/explanation/, and subsidiarity is introduced at

http://www.loyno.edu/jsri/sites/loyno.edu.jsri/files/CST-Subsidiarity-JSQ-Spr ing-2013.pdf.

o There is abundant material available put out by other Catholic educational institutions. What one thinks of the team-work can certainly be enhanced by illustrating its importance. of team work importance of As of now there are not many courses in business school curriculum that address the concepts of Solidarity and Subsidiarity.

o Managerial accounting touches upon it indirectly when addressing the concept of responsibility accounting, however teamwork is not directly touched upon by the textbook.

- In the course of learning about teamwork, it is also helpful to have students be exposed to the other side of leadership, the followership. One cannot have "chiefs" without "Indians" nor can have Brahmins without Dalits. While only a few become leaders, everyone of us is a follower. We should spend some time on promoting followership, at least a small fraction of resources commonly allocated to "leadership."

(https://www.forbes.com/sites/robasghar/2016/01/17/why-followership-is-no w-more-important-than-leadership/\#797c20505d64);

https://iveybusinessjournal.com/publication/followership-the-other-side-of-1 eadership.

\subsection{Additions to the Portfolio of Accounting \& Business Courses}

Suggesting new courses can be a problem because you run headlong into presumption that they will replace the existing courses. But new courses need be a problem, since a college curriculum is not a zero sum game. It should allow for changes since the disciplines taught themselves are constantly changing and evolving. More one learns about what students need to know, easier the adjustment become. The courses being proposed are cost-effective; can provide a great return and go a long way in making our curricular offering more innovative. 
They are likely to not preempt the existing courses since many of them are elective courses. What makes them feasible is because:

- They are meant to be summer and on-line courses.

- If offered during the academic year they could be given as "independent studies" which does not interfere with departmental budget.

- Some of the proposed courses, especially those meant to be the Third Signature Courses, can be cross-listed with other units of SHU.

- They are meant to take some of the pressure on the accounting and business courses for meeting the goals of the strategic plan. In tandem with the fleshed out competencies, it can help the core courses give optimum attention to their primary purpose of introducing students to technical knowledge.

The newest additions to my "wish-list" are those dealing with communication, more specifically, the communication of accounting and the ability of accountants to do so. Even though accounting majors are exposed through a slew of courses pertaining to preparing financial statements, they are rarely introduced to how those statements are to be communicated and impact they have on society at large.

That a large segment of my managerial accounting students cannot comprehend tests used as the mid-term and the final is for me a call to act. The students memorize formulas but cannot make sense of questions being asked of the test-takers because they are written differently than in the sample tests. It does not matter that what the questions in tests are asking are essentially similar to what many students memorized, they cannot comprehend the test question given their weakness in reading comprehension. Without the ability to comprehend the basic prose of the managerial accounting tests, it would be quixotic for anyone to think such students are ready for critical thinking \& professional judgment, writing skills, presentation skills, ethical and legal decision-making, social responsibility, teamwork, let alone the Big Data which is overtaking the profession. Rather than hyperventilate about the issue, I feel it is better to do something more than mere talk-since I do have the skills that may be usefully deployed to make a modicum of difference, but whether they get used is not under my control.

In the process of looking at how to improve students communication skills, I realized that it could be rewarding to get the English Department, the School of Arts and Communication, and the two centers of excellence in the Stillman School, Accounting and Finance to pool their assets to offer an Undergraduate Minor, a certification perhaps, in Financial Communication and Literacy, it could even be an undergraduate major or a graduate degree that combines the different units of SHU. I did not find other schools providing such an interdisciplinary program on the web.

\subsection{The List of Proposed Courses}

Below are suggested courses. They do seek to meet needs often mentioned as crucial to the disciplines of business and accounting. But are not dealt with ade- 
quately under the current courses. Whether the proposed ones would be any better is best determined by trying them out.

\subsubsection{Accounting Ethics Course}

1) Revive the accounting ethics course, which after being offered more than half a dozen times, was dropped from accounting department's active courses. It could be an on-line course, which could be taken as independent study or as a summer course.

2) I would prefer having two variations of the course: 2-credits and 3-credits: The 2-credit version would be for graduate degrees and the 3-credits would be for the undergraduates-as a senior level course, where the equivalent of 1-credit will be devoted to the overview of the Social JUSTICE.

3) In all its earlier incarnations, it used the text, Ethical Obligations and Decision-Making in Accounting: Text and Cases, by Steven M Mintz \& Roselyn E. Morris. I would use the most recent edition available.

a) It has eight chapters,

b) It is available with Connect Plus, which is well suited for on-line course.

c) Using Connect Plus, will facilitate its renewal as an as asynchronous online course,

d) The option of letting student take it either in the summer session or as an independent study during the regular academic year would limit interference with my regular teaching load: which as I mentioned is likely to be six sections of BACC 2104 a year.

e) It should be offered as a regular on-line course and not as an independent study for the summer sessions.

f) It could be an elective for non-business majors.

g) It could be taken by MBA students in the accounting track in lieu of the course they currently take, BMBA 9451.

h) As an on-line summer course, it could be aimed at students in other colleges that do not have a stand-alone accounting ethics courses.

i) Having it in the portfolio of courses will show AACSB that ethics and accountants' professional responsibilities are of concern to the department.

\subsubsection{Two Variations of the Third Signature Courses}

All students who enter the University need to take three courses, referred to as the Signature Courses

(http://academic.shu.edu/core/required\%20courses/requiredcourses.htm)

They are described below:

- CORE 1101 JOURNEY OF TRANSFORMATION: The first course in the University Core Curriculum seeks to forge a community of conversation inspired to explore perennial questions that are central to-though not exclusive to-the Catholic intellectual tradition. People throughout the different cultures and traditions of the world strive to understand the transcendent mysteries of the human journey. The world's religions, philosophies, art, music and literature are the record of that ongoing struggle for understanding. 
The first signature course invites students into this conversation via some of the great texts and other cultural artifacts that focus on transformative journeys in Catholic, Greek, Islamic, Hindu and other traditions. Students are asked to reflect upon their own transformative experiences and envision their personal journeys.

- CORE 2101 CHRISTIANTY \& CULTURE IN DIALOGUE: This course is taken by second-year students and considers the relationship between Christianity and culture through an approach based on principles of dialogue, development, and community. Texts from the Christian tradition are paired with texts from non-Christian traditions in order to demonstrate connections across cultures that influenced the development of the Catholic intellectual tradition. The course seeks to foster the development of a community of conversation through a focus on key questions and significant texts.

- CORE 3101 ENGAGING THE WORLD: The third signature courses are discipline-specific, linking the general principles of the Catholic intellectual tradition to the various fields of study offered at the university. In this way, questions emerging from the first two core courses, CORE 1101 and CORE 1201 , and find applications to the disciplines and professions taught at the University.

I would like to propose two courses to serves as the Third Signature Course for accounting majors in particular, but available to other majors as well. They could also be general electives for non-business students.

- The first would be "Discourse of Accountability: Sacramental and Prophetic Potential of Accounting. The earlier part of the paper discussed how the terms sacramental and prophetic could be applicable to accounting.

- The second course would be "The Pursuit, Use and Abuse of Wealth, A Comparative Perspectives." It would be a multi-media course that shows the opportunity cost incurred in the pursuit of wealth through text and movies like The Great Gatsby. In addition it would survey how different faith traditions have looked at the pursuit of wealth. Lastly, it would look at how accounting plays a role in the creation of wealth.

I could teach one section of the two course each semester-"discourse of accountability in spring and the "pursuit of wealth" in fall semesters.

- I would like them to be hybrid courses that rely on the Blackboard and Microsoft Teams to a great degree.

- They would also use media to a large degree. An assignment for the second course would be comparing songs about money and its connotation-"money makes the world go round" and "if I was a Wealthy Man" come to mind. The assignment would include trying to relate the emotions expressed in those songs to the "Greek Myth of King Midas and his golden touch" as well its counterpart in the scriptures of Abrahamic faiths.

In the next section proposal seeks to show how students can get to know more about the world we live in through online courses without travelling overseas. 


\subsubsection{Travel Courses: IBN Battuta Quintet}

1) These courses will make us a rare university that includes the history of trade and accounting in its portfolio of undergraduate courses. I do not think I am deluded in suggesting these could if nourished have the making of MOOC courses!

2) Trade is as older than the Scriptures, but few business majors would know it.

3) They are meant to trace the history of business, with special focus on the development of accounting.

4) They gestated largely as the project for my last sabbatical leave. They are meant to be largely summer courses.

5) Despite major efforts, the number of students who take "travel" courses is miniscule-there are many reasons why most students cannot devote their spring travelling to learn how to do business in India or Ireland-these proposed courses will provide a resource to meet the need in global village we inhabit.

The proposed quintet consists of:

a) The Silk roads. It will deal with the Silk Road-first the Old One that Marco Polo used and the Emerging One, The Belt and Road Initiative (https://www.bloomberg.com/news/articles/2019-04-28/xi-jinping-s-wins-and-1 osses-at-his-second-belt-and-road-forum: it is meant to illustrate the long history of business in that it predates the Abrahamic scriptures. Without the riches that the Silk Road brought to parts of Europe, Vasco da Gama and Christopher Columbus may never have sailed forth on their voyages of discovery. Tangentially, the course could touch on

b) Luca Pacioli's Neighborhood-birth of accounting would be its focus while located in the historic Mediterranean.

c) Doing Business alongside The British East India Company-the focus is on advent of global corporations and the chartered accounting profession in UK, using the rise of the British East India Company and its global reach.

d) Bollywood as a Global Business-a primer on how global the world has become by studying the Indian Movie Industry and its international impact. One could see this course as a study in capitalism as practiced by movie industry as well as how it represented a form of resistance to the British colonialism.

e) Dil Hay Hindustani will be exploring the Indian sub-continent for Its Investment Potential. What is unique about the course will be the lens used to study the subcontinent: the popular movie songs. The course, whose title refers to a popular song implying outer appearances notwithstanding, the heart remains Hindustani, This course will use as its structuring framework a book published in 2018, titled: Note by Note: The India Story 1947-2017, by A. Bhardwaj; S. Chishti; S. Singh

(https://scroll.in/article/891834/note-by-note-the-story-of-each-year-of-indepen dent-india-is-told-through-film-songs-in-this-book). As the link says, the book is describing the history of the sub-continent since its independence from the 
British, by using a movie song for each of the 70 years.

i) Besides the Bollywood songs, there will be significant amount of reading, viewing listening, and self-reflection-students will be encouraged to partake of South Asian cuisines on their own.

ii) The objective of the course is to help students do a SWOT analysis of the sub-continent's investment potential.

\subsubsection{Accounting Communication Courses}

- The primary reason for these courses is to broaden the communicational skills and the ability for critical thinking the accounting curriculum must provide. The ability to communicate accounting information has always been crucial, but that necessity is going to become even more of an imperative with the infusion of Analytics and Artificial Intelligence in the curriculum. It is not something the discipline can outsource away. Until such times as these courses can be brought on-line, one could use an incremental infusion to improve accounting students' competency in reading comprehension, writing, awareness of professional developments taking place, and personal accountability by the following approach.

- We could make an incremental difference in developing students' "personal accountability" and "soft skills" by having them keeping a journal in which they will record a summary/synopsis of 6 to 9 articles from the professional journals, such as the Journal of Accountancy, during the semester. These student journals could be turned in at the semester's end for grading. The grading should comprise of three levels: good, acceptable or unacceptable. Part of the grade should reflect on how well students took personal accountability in carrying out the assignments. One can provide a template for students to follow. One could also have the students keep parts of their journals online and have it available for their fellow students to browse them. This could provide a source of symbiotic benefits to students, who will gain by seeing how their fellow students are performing.

- Given my background, I feel I can help the department in this crucial area by providing a resource that does not entirely replace the challenge facing accounting professors to inculcate communication and critical thinking in their courses, but it can certainly lighten their burden. I cannot make accounting majors expert communicators or enhance their ability to discern and exercise professional judgment, I do not write like E. B. White nor speak like Walter Cronkite. Still the courses that I am willing and able to develop can make the attainment of the departmental strategic goals easier to grasp and also to assess. The proposed courses are somewhat "uncommon" in college curriculums.

- These courses would be on-line, asynchronous; Based on my education, experience and research it should be very feasible to get the courses ready, if there is interest. The actual teaching of these courses could gain by having a graduate assistant's help if they prove popular electives. 
- There is a text available, in its $11^{\text {th }}$ edition complete with instruction manual and other resources that can be used for the first three proposed courses ... There are also a plethora of resources available on-line.

- For reading assignments and to keep up with developments involving the accounting profession, students will be asked to subscribe to accounting and business journals.

- A fringe benefit of the courses would be the potential to develop an innovative program. If other units of SHU are offering a minor in "Medical $\mathrm{Hu}$ manities", why shouldn't we in Accounting play a lead role in what could be an interdisciplinary minor and certification in Financial Communication, with English Department, School of Arts and Communication, and Department of Finance from Stillman School of Business.

- I did not come up with as many hits when I searched on the web for academic programs leading to a degree in financial literacy and communication as compared to analytics or data analytics. Though not foolproof or scientific, but it is reason enough to infer on my part that teaching financial communication is not as common among the business schools, as is a major in accounting, finance or information systems. Hence it is a reason enough to explore and pioneer. Such a new program is not the primary reason for most of these proposed communication courses; even though it is quite feasible if undertaken with the School of Communication and Arts as well as the English Department. They should be of special interest to those seeking to accumulate 150 hours of course work required to qualify as a CPA.

1) Professional accounting communication, comprehension, grammar and proofreading

This could be taken as a general elective by students as a follow up to courses in English and Business writing they are required to take. This could also be on-line course, aimed at improving accounting students' communication competency something valued by employers.

It should be required or at least recommended for:

o International students with less than optimal command of English-such as those with relatively lower scores in TOEFL.

o Both international and local students who could use more accounting specific communication skills;

o Indigenous students with lower scores in their reading and writing skills;

o Perhaps those with lower than a B in their Freshmen English Course;

o If need be, it could be taken prior to starting studies;

o It should not replace the Business Communication course but supplement it.

2) Communicating accounting information $i$ (focused on managerial, cost and accounting information system)

a) Could be seen as a non-concurrent communication skills practice course for core courses in accounting as well as cost accounting and enterprise accounting courses. The course will coordinate with material taught in those 
courses-by approaching their content from a communication perspective. The cost course does not get around to issues involved in communicating impact of cost variances or even transfer pricing, which is what this course will seek to do. Similarly enterprise courses don't get to delve into documenting standard operating procedures, which this course will also do in a significant way.

b) It will have a heavy infusion of reading, writing, listening, comprehending professional discourse, self-reflection, discerning judgement and personal accountability.

c) Students will be asked to subscribe to professional accounting journals as a requirement of the course and also become student members of the professional bodies and attend their chapter meetings.

3) Communicating accounting information ii

a) Similar to Communicating Accounting Information I from above, but focused on financial accounting courses as well as the corporate annual reports, and perhaps even getting introduced to $10-\mathrm{k}$ filing.

b) A good portion of the course will study Management Discussions and Analysis (MD \& A) sections of the corporate reports using textual analytics.

c) It will be coordinated with Intermediate Accounting, possibly tax and audit courses-serving as their non-concurrent lab portion of those courses.

4) Mapping and documenting accounting information systems

a) I will use my book on the documentation the operating procedures of accounting information systems as a part of the teaching resources for the course.

b) The thesis of my book was that mapping and documenting operating procedures need not be archival, but could also be illuminative: Do not just write down the operating procedures but map them to see if they can be improved; thus putting the concept of continuous improvement into practice.

c) Course could have students map real world operating procedures and see if they could be improved and made more cost efficient.

5) The genealogy of costly mistakes and their aftermath

By using what for accountants and information engineers amounts to unstructured data, or more simply put, literary and historical texts, this proposed course will seek to study how uninformed planning or myopically abysmal implementation can have costly ramifications. In other words, the course will seek to show that the cost accounting is not limited to or even confined to dollars and cents. It will expose students to the confluence between human behavior, information, and decision making and their impact on the common good as well as the economic impact, direct and indirect. Its objective will be to promote students' critical thinking and discernment by having them analyze texts pertaining to events as minor as those "celebrated" in Alfred Tennyson's "The Charge of the Light Brigade" and Robert Southey's "The Battle of Blenheim" or as major as the partition of the Indian subcontinent or the respective British, Russian, and American involvements in Afghanistan. Such events were avoidable but were led into because of vested interests and leaving a costly impact not only on their nation but also on humanity. 
a) Potential course material to include:

i) "The Three Trillion Dollar War: The True Cost of the Iraq Conflict" by Joseph Stiglitz and Linda Bilmes (https://www.nber.org/papers/w12054.pdf).

ii) Catch-22 by Joseph Heller;

iiii) 1984 by George Orwell.

iv) Chapters from texts used for Cost Accounting and Management Accounting Control courses.

b) While the Iraqi involvement will be the prime focus of analysis for this course, however other costly mistakes can also be used as a lead up to the main topic and as topics for student projects. Among such mistakes, one could include

i) On-going Opioid Crisis

ii) The Charge of the Light Brigade

iii) The Sinking of the Titanic

iv) The Bhopal disaster

v) The Manner in which Indian subcontinent was partitioned.

vi) The Ford Pinto Gas Tank Controversy Pinto

vii) Sub-prime Mortgage debacle

viii) The Gallipoli Campaign, also known as the Dardanelles Campaign

ix) Bengal famine of 1943

x) CIA' Bringing Back the Shah of Iran

xi) Watergate

xii) Charlie Wilson's War

xiii) The Iran-Contra Affair

xiv) The Radium Girls (The Radium Girls: The Dark Story of America's Shining Women)

xv) Deepwater Horizon oil spill

c) The student will study these "costly mistakes" using "unstructured data" as exemplified in literary and historical works for analyzing how to prevent bad decisions, which beget costly consequences. Their analysis can teach students the ability to know factors directly related to making planning and control failsafe to a greater extent, and to keep them from going awry due to bad decisions and worse judgement.

d) Such a course extends the boundaries of what is construed to be cost management and its impact, which is usually measured using only cost accounting tools and financial accounting in monetary.

e) It in fact can be seen as a course concerned with the confluence of information, human behavior and decision-making.

\subsubsection{Conclusion to the Proposal}

- My rationale for proposing the triple play-besides giving something back for an association of over 30 years with the university is for the following reasons.

o To put the concept of education extending beyond the classroom into practice using something different. 
o To help relieve the accounting and core business courses from teaching not only the subject matter but helping to develop the soft skills/Skillman competencies as well.

o To implement the business school's strategic planning.

- While making the proposal, I am trying to insure that the "Triple Play" is for the most part.

o Budget neutral

o Mission-related

o Accreditation facilitating

- I will not apply for merit pay for making the proposal, I promise! I have the skills that can be brought to bear in the implementation of the Triple Play and I feel they could be put to use.

- In doing the work I am proposing, I am to get:

o A stream of scholarship and Resource for writing articles for academic journals.

o Credit for academic engagements, which combined with my re-activated CMA certification can help insure my status.

o I am certain that these can be considered "academic engagements." If bringing a guest speaker to the classroom or organizing a field trip is seen as academic engagement, then doing something similar should count similarly-one of my proposed courses is actually bringing Luca Pacioli and other famous personalities associated with the British East India Company, and Bollywood to the classrooms.

o Courses that push the boundaries of the profession and the curriculum are certainly merited, all the more so when they are for the most part, budget neutral, mission-related, and accreditation facilitating.

o It is also academic/professional engagement to work toward the goal of establishing that Communication, Social Responsibility and History of the Accounting Profession are not something that can be outsourced away but are a systemic part of what accounting encompasses: not only to count, but to account for and to communicate, accountability! They are as much a systemic part of accounting as is cost or tax.

o Stillman will gain prestige by making History, Professional Responsibilities, and Communication on par with other accounting areas such as cost, auditing, systems.

o Activities that impress upon students that in the designation for the certified public accountant (CPA), the middle word stands for the public. It should imply the CPAs are to remember the public interest.

o Lastly it might put to rest the perceptions that have followed me since I started teaching accounting albeit with a doctorate in literature. The conversation can move beyond my not being a proper accounting professor, which I admittedly am not, to what else can I do to enrich the curriculum in a way that most accounting professors do not or cannot do. 


\section{Will the Proposed Concepts Became Practice?}

An individual faculty member can have concepts and ideas, but on their own, they may not turn into practice in an academic environment. The challenge of turning concepts into practice becomes more challenging if the person proposing the concepts happens to be teaching accounting with a doctorate in literature. What happens to the concepts proposed here remains to be seen, but in the meantime knowing they have been made available to the readers provides a measure of value. As for the rest, one could say wait for the third paper. More important is to keep repeating the potential of accounting as an instrument of social justice.

\section{Conflicts of Interest}

The author declares no conflicts of interest regarding the publication of this paper.

\section{References}

[1] Henry, T.F., Murtuza, A. and Weiss, R.E. (2015) Accounting as an Instrument of Social Justice. Open Journal of Social Sciences, 3, 66-81.

https://doi.org/10.4236/jss.2015.31009

[2] Murtuza, A. (1994) Procedures Documentation Ought to Be Illuminative, Not Just Archival. Management Communication Quarterly, 8, 225-243. https://doi.org/10.1177/0893318994008002004

[3] Pava, M.L. (2010) Teaching Accounting Ethics: A Thought Experiment. Working Paper. Sy Syms School of Business, Yeshiva University, New York.

[4] United States v. Arthur Young \& Co. et al. (1984) US Supreme Court, No. 82-687.

[5] Paul II, P.J. (1991) “Centesimus Annus" on the Hundreth Anniversary of Rerum Novarum.

http://www.vatican.va/holy father/john paul ii/encyclicals/documents/hf jp-ii en c 01051991 centesimus-annus en.html

[6] Nussbaum, M. (2010) Not for Profit: Why Democracy Needs the Humanities. Princeton University Press, Princeton.

[7] Sen, A.K. (1977) Rational Fools: A Critique of the Behavioral Foundations of Economic Theory. Philosophy and Public Affairs, 6, 317-344.

[8] Ghoshal, S. (2005) Bad Management Theories Are Destroying Good Management Practices. Academy of Management Learning \& Education, 4, 75-91. https://doi.org/10.5465/amle.2005.16132558

[9] Plump, C.M. and Van Buskirk, W. (2015) Roses Are Red, Money Is Green: A Resource Review of What Poetry Brings to Business. Journal of Management Education, 39, 297-304. https://doi.org/10.1177/1052562914536052

[10] Cougar, J.D. (1995) Creative Problem Solving and Opportunity Founding. Boyd \& Fraser, Danvers.

[11] March, J. (1986) Ambiguity and Accounting: The Elusive Link between Information and Decision Making. In: Barry Cushing, Ed., Accounting and Culture, AAA, Sarasota, 31-49.

[12] Heath, L. (1987) Accounting, Communication, and the Pygmalian Syndrome. Accounting Horizons, 1, 1-8. 
[13] Arrington, C.E. and Francis, J.E. (1989) Letting the Chat Out of the Bag: Deconstruction, Privilege, and Accounting Research. Accounting, Organizations and Society, 14, 1-28. https://doi.org/10.1016/0361-3682(89)90030-5

[14] Moore, D.C. (1992) Notes towards Feminist Theories of Accounting: A View from Literary Studies. Accounting, Auditing \& Accountability Journal, 5, 99-112.

[15] Cooper, C. and Puxty, A. (1994) Reading Accounting Writing. Accounting, Organizations and Society, 19, 127-146. https://doi.org/10.1016/0361-3682(94)90015-9

[16] Walters-York, L.M. (1996) Metaphor in Accounting. Accounting, Auditing \& Accountability Journal, 9, 45-70. https://doi.org/10.1108/09513579610367242

[17] Kernan, A.B., Brooks, P. and Holquist, J.M. (1973) Man and His Fictions: An Introduction to Fiction-Making, Its Forms and Uses. Harcourt, Brace and Jovanovich, Inc., New York.

[18] Pincus, K. (1997/1998) Core Concepts of Accounting Information. McGraw-Hill, New York.

[19] Boland, R. (1996) Fantasies of Information. Advances in Public Interest Accounting, 1, 49-65.

[20] Snow, C.P. (1961) The Two Cultures and the Scientific Revolution. Cambridge University Press, Cambridge. https://doi.org/10.1063/1.3057748 